\title{
Depression as a non-causal variable risk marker in coronary heart disease
}

\author{
Anna Meijer, Marij Zuidersma and Peter de Jonge*
}

\begin{abstract}
Background: After decades of investigations, explanations for the prospective association between depression and coronary heart disease (CHD) are still incomplete.

Discussion: Depression is often suggested to be causally related to CHD. Based on the available literature, we would rather argue that depression can best be regarded as a variable risk marker, that is, a variable that fluctuates together with mechanisms leading to poor cardiovascular fitness. Despite numerous efforts, no evidence is found that manipulation of depression alters cardiovascular outcomes - a key premise for determining causality. To explain the concept of a variable risk marker, we discuss several studies on the heterogeneity of depression suggesting that depression is particularly harmful for the course of cardiovascular disease when it appears to be a physiological consequence of the cardiovascular disease itself.
\end{abstract}

Summary: We conclude that instead of depression being a causal risk factor for $\mathrm{CHD}$, the association between depression and CHD is likely confounded, at least by the cardiac disease itself.

Keywords: Cardiovascular disease, Depression, Causality, Risk marker, Risk factor

\section{Background}

For many decades, researchers and clinicians have observed an association between depression and coronary heart disease (CHD), and have tried to discover the mechanisms involved. A fair number of theories have been formulated and investigated, but no conclusive explanation exists as to why depression might lead to $\mathrm{CHD}$ and its progression. One potential explanation is that depression is causally related to the development and clinical course of CHD, either directly or through mediating pathways. Suggestive of causality, the association between depression and CHD has been consistently found across different settings and patient groups, as both etiological and prognostic associations between depression and CHD have been found in various studies of research groups worldwide [1-4]. However, in the present review we will argue that, instead of being causally involved, depression can best be defined as a variable risk marker of CHD and its progression. We will discuss this on the basis of Hill's criteria for causality [5]. In

\footnotetext{
* Correspondence: peter.de.jonge@umcg.nl

Interdisciplinary Center Psychopathology and Emotion Regulation, University of Groningen, University Medical Center Groningen, Hanzeplein 1, 9713 GZ,
} Groningen, The Netherlands addition, we will discuss current evidence in the light of the idea that symptoms and subtypes of depression that appear to be a physical consequence of the cardiac disease are most strongly predictive of adverse cardiovascular outcomes.

Principles for establishing causality have been developed by Bradford Hill [5] (Table 1), which can aid in determining the plausibility of a causal association between two variables. Below, we will discuss how the principles most relevant for the association between depression and CHD (indicated with an *), substantiate the hypothesis that depression is a variable risk marker for CHD.

The principle of strength states that causality is more likely in stronger associations. The association between depression and CHD, however, is generally moderate. Otherwise healthy people with depression have an $80 \%$ higher risk of dying of $\mathrm{CHD}$ or having a myocardial infarction (MI) than those without a depression [2]. Similarly, depressed patients with established CHD have a two times higher risk of dying of CHD or other causes $[1,2]$. Although the association of depression with development and progression of CHD is generally moderate, its magnitude is similar to that of the associations of other well-known risk factors for CHD, including 
Table 1 Principles of causality [5]

\begin{tabular}{|c|c|}
\hline Principle & Explanation \\
\hline Strength & $\begin{array}{l}\text { the stronger the association, the more likely is } \\
\text { causality* }\end{array}$ \\
\hline Consistency & $\begin{array}{l}\text { the association exists in different contexts and } \\
\text { times }\end{array}$ \\
\hline Specificity & $\begin{array}{l}\text { the association is specific for the variable and one } \\
\text { particular outcome* }\end{array}$ \\
\hline Temporality & the variable precedes the outcome* \\
\hline $\begin{array}{l}\text { Dose-response } \\
\text { relationship }\end{array}$ & $\begin{array}{l}\text { an increase in the variable results in an increase in } \\
\text { the outcome* }\end{array}$ \\
\hline Plausibility & $\begin{array}{l}\text { plausible theories/mechanisms for explaining the } \\
\text { association exist* }\end{array}$ \\
\hline Coherence & $\begin{array}{l}\text { the causal theory is coherent with existing } \\
\text { knowledge }\end{array}$ \\
\hline $\begin{array}{l}\text { Experimental } \\
\text { manipulation }\end{array}$ & $\begin{array}{l}\text { manipulation of the variable results in changes in } \\
\text { the outcome* }\end{array}$ \\
\hline Analogy & $\begin{array}{l}\text { similar associations exist between different } \\
\text { variables }\end{array}$ \\
\hline
\end{tabular}

Principles marked with an * are the principles discussed in the text.

smoking, hypertension, diabetes, obesity, dietary pattern, alcohol consumption and physical activity [6]. The causality of each of these factors (including depression), as well as their place in the causal chain towards CHD, remains to be resolved. However, the absence of a strong association suggests the association is not definitely causal. Although causality is not excluded as a possibility, it is also possible that $[7,8]$ other factors, such as cardiac disease severity and other health-related risk factors explain at least part of the association between depression and CHD.

The principle of specificity states that associations are more likely to be causal when they are specific for one variable and one outcome. According to Hill the argument of specificity is difficult to attain, and can only argue strongly in favor of causality, but can never argue against it [5]. If an association is very specific (that is, one risk factor associated with one disease only), then this is strongly supportive for causality. However, when an association is not specific, this does not necessarily argue against causality. For instance, smoking is associated with many disease outcomes, but may still be causally related to the development of some of the diseases. Like smoking, depression is associated with the outcomes of multiple diseases [9-14], and etiologically, depression is a risk factor for the development and progression of several types of disease [10], not just CHD. Moreover, other psychological problems have also been found to be associated with the development and progression of CHD, such as anxiety $[15,16]$, vital exhaustion [17,18], anger and hostility [19]. Therefore, Hill's principle of specificity has not been met, meaning that there is no support that depression is definitely a causal risk factor.
The principle of temporality states that, in a causal association, the determinant variable must precede the outcome. This principle means to determine the absence of causality rather than its presence. That is, an association in which the determinant does not precede the outcome is by definition not causal, but associations in which the determinant does precede the outcome may still be confounded. In the association between depression and CHD, most of the evidence points towards a bidirectional role of depression in CHD. In one direction, depression indeed precedes $\mathrm{CHD}$, as depression in otherwise healthy people is associated with increased risk for the onset of CHD [2,20-23], with a pooled risk ratio (RR) of between 1.5 and 2.0 [2,21,22]. In addition, in patients with existing CHD, depression is associated with an increased risk of cardiac morbidity and (cardiac) mortality $[1,2,24]$.

In the other direction, $\mathrm{CHD}$ is a potential risk factor for depression, as CHD is associated with increased prevalence of depression. An estimated $17 \%$ to $27 \%$ of CHD patients have major depressive disorder (MDD), compared with around $5 \%$ in the general population $[25,26]$. In addition, CHD in older persons without depression at baseline was found to be associated with an increased risk of developing depressive symptoms two years later [27]. Furthermore, a recent study, using the largest sample $(n=1,117,292)$ to date, found cardiovascular fitness in healthy young men to predict depression up to 40 years later, even without cardiac disease being present [28]. This latter study suggests that poor cardiovascular fitness causes depression later in life, but may also mean that both depression and CHD are caused by other factors, such as family environment and inactivity. Thus, the principle of temporality has been met as depression precedes CHD. However, this does not mean that the relation is definitely causal. Instead, the presence of the relationship in the opposite direction (that is, CHD precedes depression) rather suggests against causality.

The principle of a dose-response relationship states that an association is more likely to be causal when there is a dose-response relationship between the variable and the outcome. There is evidence for such a relationship between self-reported depressive symptoms and cardiovascular outcomes: that is, the more severe the (symptoms of) depression, the stronger the association with CHD [29,30]. However, studies comparing the prognostic value of self-reported symptoms of depression with the prognostic value of a diagnosis of MDD report mixed results. Two studies [31,32] found a diagnosis of MDD to be more strongly predictive of cardiovascular outcomes in $\mathrm{CHD}$ patients. In contrast, two other studies [33,34] found self-reported symptoms of depression to be a stronger predictor of cardiovascular 
outcomes in CHD patients. In addition, we recently found that self-reported symptoms of depression were a stronger predictor of poor cardiovascular outcomes than a diagnosis of MDD in a sample of 2,493 MI patients [30]. Finally, in our recent study of 767 MI patients, it was found that an increase of symptoms of depression immediately after an MI predicted cardiac events, whether or not these symptoms reached the level of severity of a clinical depression [35].

Thus, there is evidence for a dose-response relationship between self-reported depressive symptoms and cardiovascular outcomes, which is supportive of the idea of causality. However, a diagnosis of MDD is not necessarily a stronger predictor of cardiovascular outcomes than self-reported depressive symptoms, which seems contradictive. In research, self-report questionnaires are used more often than clinical diagnoses of depression. A characteristic of a Diagnostic Statistical Manual of Mental Disorders (DSM)-IV diagnosis of depression is that by definition, the symptoms of depression cannot be the result of a physical disease or medication use [36]. In contrast, self-report questionnaires do not distinguish between different causes of symptoms of depression. Therefore, it cannot be excluded that depressive symptoms reported on self-reported questionnaires may be an expression of CHD symptoms, which could explain the association with worse cardiovascular prognosis.

The principle of plausibility states that causality is more likely when there are plausible theories or mechanisms to explain an association. Indeed, several plausible (mediating) mechanisms have been proposed through which depression can cause poor CHD outcomes. These mechanisms include, among others, elevated inflammation or platelet activation, changes in autonomic nervous system functioning and in hypothalamic-pituitary-adrenal axis functioning $[20,37]$. They may be causally involved in the association between depression and CHD. On the other hand, instead of forming pathways between depression and CHD, they may also confound the association by underlying the development of both depression and CHD. Biological causes for depression are thought to involve vascular disease, atherosclerosis and systemic inflammation [38], which are processes also strongly involved in cardiac disease. For example, there is evidence that systemic inflammation is involved in the development of both depression and CHD [39-43].

The principle of experimental manipulation states that an association is more likely to be causal when manipulation of the determinant variable results in changes in the outcome. This may be the most important principle arguing against causality in the association between depression and CHD. Studies using depression treatment methods recommended by clinical guidelines, in which attempts have been made to improve depression
(CREATE [44], SADHART [45,47], ENRICHD [46]) have been moderately effective in doing so, but did not result in subsequent improvement of CHD outcomes. Potentially, the improvements in depression were too small to affect CHD outcomes. On the other hand, it may indicate that depression is not causal of CHD.

In summary, despite decades of research, based on the evidence for criteria of causality discussed above, evidence appears to be against depression as a causal risk factor for CHD. Depression can, therefore, best be conceptualized as a variable risk marker for $\mathrm{CHD}$ and its progression [48].

The consequences of this conceptualization of the association between depression and cardiovascular disease are, most importantly, that variations in depression are associated with variations in CHD and cardiovascular outcomes, but that experimental manipulation of depression does not change the CHD outcomes, as shown. Although depression is considered a mental disorder, for some CHD patients, some depressive symptoms may occur as a physical response to the cardiac disease. For example, fatigue is a symptom of depression, but may also be a consequence of CHD. Therefore, we propose an alternative theory, based on the fact that depression is highly heterogeneous, and typically, those symptoms and subtypes of depression that are most strongly associated with cardiac prognosis are those that are most likely a physical response to cardiac disease. The following areas of research will be discussed in light of the theory of cardiac disease severity as a confounder in the association between depression and CHD: 1) the cardiotoxicity of somatic/affective depressive symptoms; 2) the cardiotoxicity of treatment-resistant depression; and 3) residual confounding.

\section{Discussion: depression as a marker of cardiac disease severity}

\section{Somatic/affective vs. cognitive/affective symptoms}

There is evidence for two prototypical symptom clusters of depression in CHD patients, consisting of somatic/ affective and cognitive/affective symptoms. Somatic/ affective symptoms of depression are physical symptoms, such as fatigue, psychomotor changes, changes in appetite and weight, difficulty working, sleeping problems and pain [38]. Cognitive/affective symptoms include symptoms such as depressed mood, loss of interest, suicidal ideation, pessimism, interpersonal sensitivity and feelings of failure, guilt, self-dislike, self-accusation and self-criticism [38]. Due to their somatic nature, somatic/ affective symptoms may conceptually show greater overlap with cardiac disease than cognitive/affective depressive symptoms. That is, somatic/affective symptoms may be a direct (fatigue) or indirect (work difficulties) physical consequence of the cardiac disease. If cardiac disease 
is an important confounder in the association between depression and cardiac prognosis, then particularly somatic/affective depressive symptoms should be related to worse cardiac prognosis and to pathophysiological underlying processes.

Somatic/affective symptoms indeed are more strongly associated with worsened cardiac outcomes than cognitive/affective symptoms [38]. In a study of patients with stable CHD, each somatic symptom of depression was associated with a $14 \%$ higher risk of new cardiac events after adjustment for cardiac risk factors, whereas cognitive symptoms of depression were not [49]. In another study, somatic/affective and appetitive symptoms of depression were both associated with, respectively, 35\% and $42 \%$ increased risk of cardiac mortality and morbidity, but cognitive/affective symptoms were not [50]. In MI patients, somatic/affective symptoms were found to be more strongly associated with cardiac health status (left ventricular ejection fraction (LVEF), Killip class and previous $\mathrm{MI}$ ) and cardiac prognosis and mortality than cognitive/affective symptoms in several studies [51-53]. Smolderen et al. found that somatic symptoms of depression were associated with long-term outcomes in MI patients, but cognitive symptoms of depression were not [54]. Recently, Bekke-Hansen et al. found that somatic/ affective symptoms at 12 months after an MI predicted all-cause and cardiac mortality, but no such association was found for cognitive/affective symptoms [55]. In contrast, two studies found cognitive/affective depressive symptoms to be more predictive of cardiac outcomes $[56,57]$. However, these two studies were both performed in coronary artery bypass patients evaluating depressive symptoms postoperatively, whereas all former studies evaluated depressive symptoms in CHD patients (either stable CHD or within several months after an acute cardiac event). One other study in MI patients found three out of four somatic symptoms of depression (fatigue, appetite problems and psychomotor changes), but also two out of five cognitive depressive symptoms (lack of interest and suicidal ideation) to be associated with poor cardiac outcomes [58]. However, this latter study was the only study that assessed depressive symptoms with a diagnostic interview. Thus, in all studies on CHD patients, except those just after coronary artery bypass grafting (CABG) surgery, self-reported somatic/affective symptoms of depression predicted poor cardiac outcomes more than cognitive/affective symptoms. This is suggestive of a specific link between self-reported somatic/affective symptoms and CHD.

Somatic/affective symptoms may be associated more with different underlying mechanisms than cognitive/ affective symptoms, resulting in somatic affective symptoms being particularly cardiotoxic [59]. Most studies only find a link between physiological processes and somatic/affective symptoms. One study found that low heart rate variability, which is associated with worsened cardiac outcomes, was associated with somatic/affective symptoms but not with cognitive/affective symptoms of depression in patients with stable CHD [60]. Also, in several studies, somatic/affective symptoms, but not cognitive/affective symptoms, have been associated with atherosclerosis in otherwise healthy people $[61,62]$, and with visceral obesity [63]. In addition, otherwise healthy patients with atypical depression (increased appetite, increased sleep) were found to have higher body mass index and higher risk of metabolic syndrome than patients with melancholic depression [64]. Apparently, somatic/affective, but not cognitive symptoms of depression are associated with biological mechanisms involved in CHD. This link may, therefore, be particularly strong in patients with a recent cardiac event, such as a myocardial infarction. Delisle et al., for example, found that hospitalized depressed MI patients had higher Beck Depression Inventory somatic symptom scores than did depressed psychiatry outpatients [65]. Together, findings on the relationship of somatic/affective symptoms with cardiac prognosis and underlying biological mechanisms suggest that somatic/affective depressive symptoms are a physiological consequence of $\mathrm{CHD}$, which explains at least part of the association between the two.

Cognitive/affective and somatic/affective symptoms often occur together. These two symptom clusters of depression are in fact continuous phenomena, making it difficult to give an exact figure of the prevalence of the two subtypes and their co-occurrence. We believe that there will be continuous transitions between two prototypical forms of depression, while any mixture of cognitive and somatic affective symptoms may develop in a particular individual with CHD [38]. Both clusters may thus be present at the same time, in some cases there may be a sequential pattern of symptoms, and in some a clear predominance of one of the clusters may be present. Future research should further explore these issues in CHD patients. Thus, although both symptom profiles may be present within the same individual, the somatic/affective symptom profile is often found to be associated with worse cardiovascular prognosis, independent of the cognitive/affective symptom profile.

\section{Treatment-resistant depression and cardiac prognosis}

Another subtype of depression that is related to cardiac disease is treatment-resistant depression, which is particularly associated with the risk of poor cardiovascular outcomes $[38,66]$. In the Montreal Heart Attack Readjustment Trial (M-Hart), the effects of a psychosocial nursing intervention on psychological distress, mortality and new cardiovascular events were evaluated in 1,376 post-MI patients [67]. Patients who showed persisting or 
worsening psychological distress despite the intervention had an increased risk of dying or of cardiac hospital readmissions within the subsequent year [68]. Milani et al. evaluated the effects of a cardiac rehabilitation program with exercise training on depressive symptoms and allcause mortality in CHD patients. They found patients with persisting or increasing depressive symptoms during the rehabilitation program had higher all-cause mortality rates than patients with decreasing or constantly low levels of depressive symptoms [69]. More recently, this finding was replicated in CHD patients with additional heart failure [70]. The Myocardial Infarction and Depression Intervention Trial (MIND-IT) evaluated the effects of the antidepressants mirtazapine and citalopram on depression and risk of new cardiac events in depressed MI patients. Patients who did not respond to the treatment significantly more often had a new cardiac event (25.6\% vs. $7.4 \%$ ) compared with those who did respond [71]. The Sertraline Antidepressant Heart Attack Trial (SADHART) included depressed acute coronary syndrome patients in a sixmonth randomized treatment trial of sertraline vs. placebo. Patients with treatment-resistant depression were at increased risk of all-cause mortality up until eight years after treatment initiation, and this increased risk was also found for patients with persisting depression who were treated with placebo [45,47]. Similar results were found in the Enhancing Recovery in Coronary Heart Disease (ENRICHD) trial, which evaluated the effects of six months' treatment with cognitive behavioral therapy supplemented with sertraline on cardiovascular outcomes and mortality in depressed MI-patients. Patients in whom the depressive symptoms did not improve had increased mortality rates compared to those whose depressive symptoms did improve [72,73]. Recently, the investigators showed that this increased risk was due to the persistence of somatic/affective depressive symptoms, but not to cognitive/affective depressive symptoms [73].

One explanation for the association between treatmentresistant depression and worse cardiac prognosis is that underlying factors relate to both the treatment nonresponse and the poor cardiac prognosis, such as the cardiac disease itself. That is, patients with treatmentresistant depression may have a constantly severe or even deteriorating underlying cardiac disease. A constantly severe or deteriorating heart disease would be reflected in depressive symptoms that persist over time, do not respond to traditional depression treatment, and that are associated with worse cardiovascular prognosis. This is consistent with the hypothesis that depression is a variable risk marker for cardiac outcomes.

\section{Residual confounding}

If depression were a variable risk marker, one would expect the association between depression and cardiac prognosis to be attenuated after adjustment for potential confounders, like the severity of the cardiac disease. Still, the association between depressive symptoms and cardiovascular prognosis remains, even after adjustment for severity of the heart disease and other potential confounders $[1,2]$. This suggests that depression is an independent risk factor for CHD. Instead of this, we would rather argue that this is the result of incomplete adjustment. When cardiac disease severity is incompletely or imprecisely measured, statistical adjustment for cardiac disease severity may lead to an underestimation of its underlying role. This phenomenon is known as residual confounding [74] (that is, due to imprecise measurement of parameters) or unmeasured confounding (that is, due to unmeasured parameters). A simulation study showed that associations found in observational studies, such as those between depression and cardiac prognosis, can be generated by residual and unmeasured confounding alone [75]. In contrast to observational studies, experimental studies with randomized designs minimize confounding by unmeasured as well as measured factors. If an association is found in an observational study, but not in an experimental study, it is likely that unmeasured or imprecisely measured factors confound the association. This may be the case for depression and cardiac prognosis, as observational studies consistently find an association between depression and cardiac prognosis [1-3], but experimental manipulation of the depression in a randomized trial does not affect cardiac prognosis [45-47,76].

\section{Conclusion}

We suggest that, based on current evidence, depression can best be defined as a non-causal variable risk marker for CHD, and causality cannot be established. In addition, recent literature on the heterogeneity of depression demonstrates that subtypes of depression that are specifically cardiotoxic may be present in some patients. Although we believe that particularly the role of underlying cardiovascular disease processes in explaining the association between (subtypes of) depression and CHD is currently underrated, there are likely additional mechanisms underlying the association. As the association between depression and CHD is complex, and depression is strongly heterogeneous in CHD patients, different mechanisms and combinations of mechanisms are probably involved in different patients.

\section{Abbreviations}

CABG: Coronary artery bypass grafting; CHD: Coronary heart disease; CREATE: Cardiac randomized evaluation of antidepressant and psychotherapy fficacy; ENRICHD: Enhancing recovery in coronary heart disease; LVEF: Left ventricular ejection fraction; MDD: Major depressive disorder; M-HART: Montreal heart attach readjustment trial; MI: Myocardial infarction; MIND-IT: Myocardial infarction and depression intervention trial; SADHART: Sertraline antidepressant heart attack randomized trial. 


\section{Competing interests}

The authors declare they have no competing interests.

\section{Authors' contributions}

AM drafted the manuscript. PdJ conceived of the paper, and critically reviewed and revised the manuscript. $M Z$ assisted in drafting the manuscript and critically reviewed and revised the paper. All authors read and approved the final manuscript.

\section{Acknowledgements}

This review is the final and aggregated output of a VIDI grant from the Dutch Medical Research Council (grant 016.086.397).

\section{Received: 14 November 2012 Accepted: 17 April 2013}

Published: 15 May 2013

\section{References}

1. Meijer A, Conradi HJ, Bos EH, Thombs BD, van Melle JP, de Jonge P: Prognostic association of depression following myocardial infarction with mortality and cardiovascular events: a meta-analysis of 25 years of research. Gen Hosp Psychiatry 2011, 33:203-216.

2. Nicholson A, Kuper $H$, Hemingway $H$ : Depression as an aetiologic and prognostic factor in coronary heart disease: a meta-analysis of 6362 events among 146538 participants in 54 observational studies. Eur Heart J 2006, 27:2763-2774.

3. Barth J, Schumacher M, Herrmann-Lingen C: Depression as a risk factor for mortality in patients with coronary heart disease: a meta-analysis. Psychosom Med 2004, 66:802-813.

4. Musselman DL, Evans DL, Nemeroff CB: The relationship of depression to cardiovascular disease: epidemiology, biology, and treatment. Arch Gen Psychiatry 1998, 55:580-592.

5. Bradford Hill A: The environment and disease: association or causation? Proc R Soc Med 1965, 58:295-300.

6. Yusuf S, Hawken S, Ounpuu S, Dans T, Avezum A, Lanas F, McQueen M, Budaj A, Pais P, Varigos J, Lisheng L, INTERHEART Study Investigators: Effect of potentially modifiable risk factors associated with myocardial infarction in 52 countries (the INTERHEART study): case-control study. Lancet 2004, 364:937-952.

7. Bot M, Pouwer F, Zuidersma M, van Melle JP, de Jonge P: Association of coexisting diabetes and depression with mortality after myocardial infarction. Diabetes Care 2012, 35:503-509.

8. Centers for disease control and prevention: smoking \& tobacco use http://www.cdc.gov/tobacco/basic_information/health_effects/cancer/.

9. Evans DL, Charney DS, Lewis L, Golden RN, Gorman JM, Krishnan KR, Nemeroff CB, Bremner JD, Carney RM, Coyne JC, Delong MR, Frasure-Smith N, Glassman AH, Gold PW, Grant I, Gwyther L, Ironson G, Johnson RL, Kanner AM, Katon WJ, Kaufmann PG, Keefe FJ, Ketter T, Laughren TP, Leserman J, Lyketsos CG, McDonald WM, McEwen BS, Miller AH, Musselman $D$, et al: Mood disorders in the medically ill: scientific review and recommendations. Biol Psychiatry 2005, 58:175-189.

10. World Health Organization: Investing in Mental Health. Geneva: World Health Organization; 2003.

11. Hedayati SS, Minhajuddin AT, Afshar M, Toto RD, Trivedi MH, Rush AJ: Association between major depressive episodes in patients with chronic kidney disease and initiation of dialysis, hospitalization, or death. JAMA 2010, 303:1946-1953.

12. Markowitz SM, Gonzalez JS, Wilkinson JL, Safren SA: A review of treating depression in diabetes: emerging findings. Psychosomatics 2011, 52:1-18.

13. Pinquart M, Duberstein PR: Depression and cancer mortality: a metaanalysis. Psychol Med 2010, 40:1797-1810.

14. Fritzsche A, Clamor A, von Leupoldt A: Effects of medical and psychological treatment of depression in patients with COPD-a review. Respir Med 2011, 105:1422-1433.

15. Roest AM, Martens EJ, de Jonge P, Denollet J: Anxiety and risk of incident coronary heart disease: a meta-analysis. J Am Coll Cardiol 2010, 56:38-46.

16. Roest AM, Martens EJ, Denollet J, de Jonge P: Prognostic association of anxiety post myocardial infarction with mortality and new cardiac events: a meta-analysis. Psychosom Med 2010, 72:563-569.

17. Kop WJ, Appels AP, Mendes de Leon CF, de Swart HB, Bar FW: Vital exhaustion predicts new cardiac events after successful coronary angioplasty. Psychosom Med 1994, 56:281-287.
18. Williams JE, Mosley TH Jr, Kop WJ, Couper DJ, Welch VL, Rosamond WD: Vital exhaustion as a risk factor for adverse cardiac events (from the Atherosclerosis Risk In Communities [ARIC] study). Am J Cardio/ 2010, 105:1661-1665.

19. Chida $Y$, Steptoe A: The association of anger and hostility with future coronary heart disease: a meta-analytic review of prospective evidence. J Am Coll Cardiol 2009, 53:936-946.

20. Frasure-Smith $N$, Lesperance F: Depression and cardiac risk: present status and future directions. Heart 2010, 96:173-176.

21. Rugulies R: Depression as a predictor for coronary heart disease. A review and meta-analysis. Am J Prev Med 2002, 23:51-61.

22. Wulsin $L R$, Singal $B M$ : Do depressive symptoms increase the risk for the onset of coronary disease? A systematic quantitative review. Psychosom Med 2003, 65:201-210.

23. Kuper $H$, Marmot $M$, Hemingway $H$ : Systematic review of prospective cohort studies of psychosocial factors in the etiology and prognosis of coronary heart disease. Semin Vasc Med 2002, 2:267-314.

24. van Melle JP, de Jonge P, Spijkerman TA, Tijssen JG, Ormel J, van Veldhuisen DJ, van den Brink RH, van den Berg MP: Prognostic association of depression following myocardial infarction with mortality and cardiovascular events: a meta-analysis. Psychosom Med 2004, 66:814-822.

25. Rudisch B, Nemeroff CB: Epidemiology of comorbid coronary artery disease and depression. Biol Psychiatry 2003, 54:227-240.

26. Thombs BD, Bass EB, Ford DE, Stewart KJ, Tsilidis KK, Patel U, Fauerbach JA, Bush DE, Ziegelstein RC: Prevalence of depression in survivors of acute myocardial infarction. J Gen Intern Med 2006, 21:30-38.

27. Mast BT, Miles T, Penninx BW, Yaffe K, Rosano C, Satterfield S, Ayonayon HN, Harris T, Simonsick EM: Vascular disease and future risk of depressive symptomatology in older adults: findings from the health, aging, and body composition study. Biol Psychiatry 2008, 64:320-326.

28. Åberg MA, Waern M, Nyberg J, Pedersen NL, Bergh Y, Åberg ND, Nilsson M, Kuhn HG, Torén K: Cardiovascular fitness in males at age 18 and risk of serious depression in adulthood: Swedish prospective population-based study. Br J Psychiatry 2012, 201:352-359.

29. Lesperance F, Frasure-Smith N, Talajic M, Bourassa MG: Five-year risk of cardiac mortality in relation to initial severity and one-year changes in depression symptoms after myocardial infarction. Circulation 2002, 105:1049-1053.

30. Zuidersma $\mathrm{M}$, Conradi HJ, van Melle J, Ormel J, de Jonge P: Self-reported depressive symptoms, diagnosed clinical depression, and cardiac morbidity and mortality after myocardial infarction. Int J Cardiol 2012 [Epub ahead of print.].

31. Penninx BW, Beekman AT, Honig A, Deeg DJ, Schoevers RA, van Eijk JT, van Tilburg W: Depression and cardiac mortality: results from a communitybased longitudinal study. Arch Gen Psychiatry 2001, 58:221-227.

32. Frasure-Smith N, Lesperance F: Depression and anxiety as predictors of 2year cardiac events in patients with stable coronary artery disease. Arch Gen Psychiatry 2008, 65:62-71.

33. Frasure-Smith N, Lesperance F, Talajic M: Depression and 18-month prognosis after myocardial infarction. Circulation 1995, 91:999-1005.

34. Whooley MA, de Jonge P, Vittinghoff E, Otte C, Moos R, Carney RM, Ali S, Dowray S, Na B, Feldman MD, Schiller NB, Browner WS: Depressive symptoms, health behaviors, and risk of cardiovascular events in patients with coronary heart disease. JAMA 2008, 300:2379-2388.

35. Zuidersma M, Ormel J, Conradi HJ, de Jonge P: An increase in depressive symptoms after myocardial infarction predicts new cardiac events irrespective of depressive symptoms before myocardial infarction. Psychol Med 2012, 42:683-693.

36. American Psychiatric Association: Diagnostic and Statistical Manual of Mental Disorders DSM-IV-Tr. 4th edition. Washington DC: American Psychiatric Association; 2000.

37. Carney RM, Freedland KE, Miller GE, Jaffe AS: Depression as a risk factor for cardiac mortality and morbidity: a review of potential mechanisms. J Psychosom Res 2002, 53:897-902.

38. Ormel J, de Jonge P: Unipolar depression and the progression of coronary artery disease: toward an integrative model. Psychother Psychosom 2011, 80:264-274.

39. Dantzer R, O'Connor JC, Freund GG, Johnson RW, Kelley KW: From inflammation to sickness and depression: when the immune system subjugates the brain. Nat Rev Neurosci 2008, 9:46-56.

40. IL6R Genetics Consortium Emerging Risk Factors Collaboration, Sarwar N, Butterworth AS, Freitag DF, Gregson J, Willeit P, Gorman DN, Gao P, 
Saleheen D, Rendon A, Nelson CP, Braund PS, Hall AS, Chasman DI, Tybjaerg-Hansen A, Chambers JC, Benjamin EJ, Franks PW, Clarke R, Wilde AA, Trip MD, Steri M, Witteman JC, Qi L, van der Schoot CE, de Faire U, Erdmann J, Stringham HM, Koenig W, Rader DJ, Melzer D, et al: Interleukin6 receptor pathways in coronary heart disease: a collaborative metaanalysis of 82 studies. Lancet 2012, 379:1205-1213.

41. Emerging Risk Factors Collaboration, Kaptoge S, Di Angelantonio E, Lowe G, Pepys MB, Thompson SG, Collins R, Danesh J: C-reactive protein concentration and risk of coronary heart disease, stroke, and mortality: an individual participant meta-analysis. Lancet 2010, 375:132-140.

42. Danesh J, Wheeler JG, Hirschfield GM, Eda S, Eiriksdottir G, Rumley A, Lowe $\mathrm{GD}$, Pepys MB, Gudnason V: C-reactive protein and other circulating markers of inflammation in the prediction of coronary heart disease. N Engl J Med 2004, 350:1387-1397.

43. Malik I, Danesh J, Whincup P, Bhatia V, Papacosta O, Walker M, Lennon L, Thomson A, Haskard D: Soluble adhesion molecules and prediction of coronary heart disease: a prospective study and meta-analysis. Lancet 2001, 358:971-976.

44. Lesperance F, Frasure-Smith N, Koszycki D, Laliberté MA, van ZyI LT, Baker B, Swenson JR, Ghatavi K, Abramson BL, Dorian P, Guertin MC, CREATE investigators: Effects of citalopram and interpersonal psychotherapy on depression in patients with coronary artery disease: the Canadian Cardiac Randomized Evaluation of Antidepressant and Psychotherapy Efficacy (CREATE) trial. JAMA 2007, 297:367-379. Erratum in: JAMA 2007, 298:40.

45. Glassman AH, O'Connor CM, Califf RM, Swedberg K, Schwartz P, Bigger JT Jr, Krishnan KR, van Zyl LT, Swenson JR, Finkel MS, Landau C, Shapiro PA, Pepine CJ, Mardekian J, Harrison WM, Barton D, Mclvor M, Sertraline Antidepressant Heart Attack Randomized Trial (SADHEART) Group: Sertraline treatment of major depression in patients with acute $\mathrm{MI}$ or unstable angina. JAMA 2002, 288:701-709.

46. Berkman LF, Blumenthal J, Burg M, Carney RM, Catellier D, Cowan MJ, Czajkowski SM, DeBusk R, Hosking J, Jaffe A, Kaufmann PG, Mitchell P, Norman J, Powell LH, Raczynski JM, Schneiderman N, Enhancing Recovery in Coronary Heart Disease Patients Investigators (ENRICHD): Effects of treating depression and low perceived social support on clinical events after myocardial infarction: the Enhancing Recovery in Coronary Heart Disease Patients (ENRICHD) Randomized Trial. JAMA 2003, 289:3106-3116.

47. Glassman AH, Bigger JT Jr, Gaffney M: Psychiatric characteristics associated with long-term mortality among 361 patients having an acute coronary syndrome and major depression: seven-year follow-up of SADHART participants. Arch Gen Psychiatry 2009, 66:1022-1029.

48. Kraemer HC, Kazdin AE, Offord DR, Kessler RC, Jensen PS, Kupfer DJ: Coming to terms with the terms of risk. Arch Gen Psychiatry 1997, 54:337-343.

49. Hoen PW, Whooley MA, Martens EJ, Na B, van Melle JP, de Jonge P: Differential associations between specific depressive symptoms and cardiovascular prognosis in patients with stable coronary heart disease. J Am Coll Cardiol 2010, 56:838-844.

50. Linke SE, Rutledge T, Johnson BD, Vaccarino V, Bittner V, Cornell CE, Eteiba W, Sheps DS, Krantz DS, Parashar S, Bairey Merz CN: Depressive symptom dimensions and cardiovascular prognosis among women with suspected myocardial ischemia: a report from the National Heart, Lung, and Blood Institute-sponsored Women's Ischemia Syndrome Evaluation. Arch Gen Psychiatry 2009, 66:499-507.

51. de Jonge P, Ormel J, van den Brink RH, van Melle JP, Spijkerman TA, Kuijper A, van Veldhuisen DJ, van den Berg MP, Honig A, Crijns HJ, Schene AH: Symptom dimensions of depression following myocardial infarction and their relationship with somatic health status and cardiovascular prognosis. Am J Psychiatry 2006, 163:138-144.

52. Martens EJ, Hoen PW, Mittelhaeuser M, de Jonge P, Denollet J: Symptom dimensions of post-myocardial infarction depression, disease severity and cardiac prognosis. Psychol Med 2010, 40:807-814.

53. Roest AM, Thombs BD, Grace SL, Stewart DE, Abbey SE, de Jonge P: Somatic/affective symptoms, but not cognitive/affective symptoms, of depression after acute coronary syndrome are associated with 12-month all-cause mortality. J Affect Disord 2011, 131:158-163.

54. Smolderen KG, Spertus JA, Reid KJ, Buchanan DM, Krumholz HM, Denollet J, Vaccarino V, Chan PS: The association of cognitive and somatic depressive symptoms with depression recognition and outcomes after myocardial infarction. Circ Cardiovasc Qual Outcomes 2009, 2:328-337.
55. Bekke-Hansen S, Trockel M, Burg MM, Taylor CB: Depressive symptom dimensions and cardiac prognosis following myocardial infarction: results from the ENRICHD clinical trial. Psychol Med 2012, 42:51-60.

56. Tully PJ, Winefield HR, Baker RA, Turnbull DA, de Jonge P: Confirmatory factor analysis of the Beck Depression Inventory-II and the association with cardiac morbidity and mortality after coronary revascularization. $J$ Health Psychol 2011, 16:584-595.

57. Connerney I, Sloan RP, Shapiro PA, Bagiella E, Seckman C: Depression is associated with increased mortality 10 years after coronary artery bypass surgery. Psychosom Med 2010, 72:874-881.

58. Hoen PW, Conradi HJ, Denollet J, Martens EJ, de Jonge P: Interview-based ratings of somatic and cognitive symptoms of depression and their impact on cardiovascular prognosis. Psychother Psychosom 2010, 79:319-320.

59. Kupper N, Widdershoven JW, Pedersen SS: Cognitive/affective and somatic/affective symptom dimensions of depression are associated with current and future inflammation in heart failure patients. $J$ Affect Disord 2012, 136:567-576.

60. de Jonge $P$, Mangano D, Whooley MA: Differential association of cognitive and somatic depressive symptoms with heart rate variability in patients with stable coronary heart disease: findings from the Heart and Soul Study. Psychosom Med 2007, 69:735-739.

61. Bus BA, Marijnissen RM, Holewijn S, Franke B, Purandare N, de Graaf J, den Heijer M, Buitelaar JK, Voshaar RC: Depressive symptom clusters are differentially associated with atherosclerotic disease. Psychol Med 2011, 41:1419-1428.

62. Stewart JC, Janicki DL, Muldoon MF, Sutton-Tyrrell K, Kamarck TW: Negative emotions and 3-year progression of subclinical atherosclerosis. Arch Gen Psychiatry 2007, 64:225-233.

63. Marijnissen RM, Bus BA, Holewijn S, Franke B, Purandare N, de Graaf J, den Heijer M, Buitelaar JK, Oude Voshaar RC: Depressive symptom clusters are differentially associated with general and visceral obesity. J Am Geriatr Soc 2011, 59:67-72.

64. Lamers F, de Jonge P, Nolen WA, Smit JH, Zitman FG, Beekman AT, Penninx BW: Identifying depressive subtypes in a large cohort study: results from the Netherlands Study of Depression and Anxiety (NESDA). J Clin Psychiatry 2010, 71:1582-1589.

65. Delisle VC, Beck AT, Ziegelstein RC, Thombs BD: Symptoms of heart disease or its treatment may increase Beck Depression Inventory Scores in hospitalized post-myocardial infarction patients. J Psychosom Res 2012, 73:157-162.

66. Carney RM, Freedland KE: Treatment-resistant depression and mortality after acute coronary syndrome. Am J Psychiatry 2009, 166:410-417.

67. Frasure-Smith $\mathrm{N}$, Lesperance $F$, Prince $\mathrm{RH}$, Verrier $\mathrm{P}$, Garber RA, Juneau M, Wolfson C, Bourassa MG: Randomised trial of home-based psychosocial nursing intervention for patients recovering from myocardial infarction. Lancet 1997, 350:473-479.

68. Cossette S, Frasure-Smith N, Lesperance F: Clinical implications of a reduction in psychological distress on cardiac prognosis in patients participating in a psychosocial intervention program. Psychosom Med 2001, 63:257-266.

69. Milani RV, Lavie CJ: Impact of cardiac rehabilitation on depression and its associated mortality. Am J Med 2007, 120:799-806.

70. Milani RV, Lavie CJ, Mehra MR, Ventura HO: Impact of exercise training and depression on survival in heart failure due to coronary heart disease. Am J Cardiol 2011, 107:64-68.

71. de Jonge P, Honig A, van Melle JP, Schene AH, Kuyper AM, Tulner D, Schins A, Ormel J, MIND-IT Investigators: Nonresponse to treatment for depression following myocardial infarction: association with subsequent cardiac events. Am J Psychiatry 2007, 164:1371-1378.

72. Carney RM, Blumenthal JA, Freedland KE, Youngblood M, Veith RC, Burg MM, Cornell C, Saab PG, Kaufmann PG, Czajkowski SM, Jaffe AS, ENRICHD Investigators: Depression and late mortality after myocardial infarction in the Enhancing Recovery in Coronary Heart Disease (ENRICHD) study. Psychosom Med 2004, 66:466-474.

73. Roest AM, Carney RM, Freedland KE, Martens EJ, Denollet J, de Jonge P: Changes in cognitive versus somatic symptoms of depression and event-free survival following myocardial infarction in the Enhancing Recovery In Coronary Heart Disease (ENRICHD) study. J Affect Disord 2013. doi:10.1016/j.jad.2013.02.008.

74. Christenfeld NJ, Sloan RP, Carroll D, Greenland S: Risk factors, confounding, and the illusion of statistical control. Psychosom Med 2004, 66:868-875. 
75. Fewell Z, Davey Smith G, Sterne JA: The impact of residual and unmeasured confounding in epidemiologic studies: a simulation study. Am J Epidemiol 2007, 166:646-655.

76. Thombs BD, de Jonge P, Coyne JC, Whooley MA, Frasure-Smith N, Mitchell AJ, Zuidersma M, Eze-Nliam C, Lima BB, Smith CG, Soderlund K, Ziegelstein RC: Depression screening and patient outcomes in cardiovascular care: a systematic review. JAMA 2008, 300:2161-2171.

doi:10.1186/1741-7015-11-130

Cite this article as: Meijer et al:: Depression as a non-causal variable risk

marker in coronary heart disease. BMC Medicine 2013 11:130.

\section{Submit your next manuscript to BioMed Central and take full advantage of:}

- Convenient online submission

- Thorough peer review

- No space constraints or color figure charges

- Immediate publication on acceptance

- Inclusion in PubMed, CAS, Scopus and Google Scholar

- Research which is freely available for redistribution 